\title{
QUO-VADIS MULTIKULTURALISME DALAM HISTORIS DAN HISTORIOGRAFI SENI RUPA INDONESIA
}

\author{
Kasiyan \\ Jurusan dan Program Studi Pendidikan Seni Rupa \\ Fakultas Bahasa dan Seni Universitas Negeri Yogyakarta \\ Email: kasiyan1@yahoo.com
}

\begin{abstract}
The multicultural paradigm has become a frequent topic of discussion as its key values con-cerning the spirit of respecting differences. The fact that differences are commonly considered a threat in Modernist philosophy has led particularity space becoming increasingly negated. In an Indonesian context, multiculturalism has a long historical basis, one tied inexorably with the nation's nature as an absolute constructed from plural complexity. Hence, multiculturalism should be involved in every cultural activity, at any time and in any context, including the Fine Arts. Within this discipline, multiculturalism has been the main concern, considering that the Fine Arts deal with creativity and aesthetic terminologies which cannot be separated from the discussion of differences. What then becomes the main concern is the fact that this multicultural aspect has unconsciously become a quo-vadis reality in other cultural mainstreams.
\end{abstract}

Keywords: Quo-vadis, Multiculturalism, Historical, Historiography, Fine Art

\begin{abstract}
ABSTRAK
Paradigma multikultural akhir-akhir ini banyak mendapatkan perhatian karena di dalamnya sarat dengan nilai-nilai yang menjanjikan berkembangnya peradaban yang dijiwai spirit penghargaan atas perbedaan. Hal ini mengingat, persoalan perbedaan kerap ditempatkan sebagai ancaman dalam filsafat Modernisme, yang mengakibatkan ruang keniscayaan partikularitas menjadi semakin ternegasikan. Dalam konteks keindonesiaan, multikulturalisme mempunyai akar historis yang panjang, sejalan dengan absolutitas negeri ini yang historisitasnya memang juga dikonstruksi dengan kompleksitas yang plural. Oleh karena itu, eksistensi multikulturalisme layak untuk terus disemaikan dalam setiap kerja kebudayaan, termasuk dalam hal ini adalah dalam disiplin Seni Rupa. Dalam disiplin Seni Rupa, multikulturalisme bahkan sejak lama telah menjadi salah satu roh terpenting, karena memang disiplin ini eksistensiya berkutat pada terminologi kreativitas dan estetika, yang salah satu esensinya adalah menyoal teks perbedaan sebagai jangkar aras kesadarannya. Yang menjadi persoalan kemudian adalah potensi multikulturalisme dalam disiplin Seni Rupa ini, juga menjadi realitas quo-vadis sebagaimana mainstream kebudayaan lain pada umumnya.
\end{abstract}

Kata Kunci: Quo-vadis, Multikulturalisme, Historis, Historiografi, Seni Rupa 


\section{PENGANTAR}

Multikultural, sebagai sebuah paradigma dalam praksis kebudayaan yang pertama kali semaian wacananya hadir dalam kesadaran kebudayaan Barat, sejak tahun 60 dan awal 70-an (May, 1999: 1), hingga saat ini masih tetap menarik untuk terus ditafsir dan ditafsir ulang, hampir di semua belahan dunia. Penyebabnya adalah, di dalamnya terkandung nilai-nilai yang relatif potensial menjanjikan bagi tumbuhkembangnya konstruksi harmoni peradaban yang lebih berkeadilan karena di dalamnya dijiwai oleh spirit yang sarat dengan penghargaan atas perbedaan di tengah-tengah kebersamaan (unity and harmony in diversity), sebagaimana kodrat absolut kebudayaan semesta raya ini.

Terminologi perbedaan, yang sebenarnya lebih merupakan satu keniscayaan, justru menjadi domain terdepan bagi pemicu sekian deret problem serius dalam kebudayaan. Hal ini disebabkan oleh adanya salah tafsir atas teks perbedaan itu sendiri, yakni bukan sebagai berkah, namun lebih ditempatkan sebagai ancaman keharmonisan dan kebersamaan sebagaimana yang menjadi kutukan dalam filsafat modernisme selama ini. Dengan segala arogansi paham universalismenya, modernisme tidak mampu mengantarkan harapan pencerahan peradaban, sebagaimana semangat awal yang membimbingnya sejak zaman renaissance, karena dengan amat semena-mena telah menegasikan ruang keniscayaan partikularitas dan bahkan di banyak jejak empirisnya dan fenomena tersebut kerap terekspresikan secara amat anarkis.

Dalam konteks ke-Indonesiaan, multikulturalisme telah mempunyai akar historis yang amat panjang sejalan dengan realitas absolut negeri ini yang dikonstruksi dengan kompleksitas yang juga plural, baik dari sisi etnis, budaya, bahasa, seni, keyakinan, dan sederet pilar lainnya. Bahkan, jauh hari sebelum konsep sebuah nation-state dengan segala narasi dan atribusi ke-Indonesiaan termanifesto secara de yure, multikulturalisme juga telah menjadi pilar penyangga utama bagi sejarah kejaya-rayaan kerajaan-ker- ajaan Nusantara, seperti Majapahit dan Sriwijaya. Fakta ini semakin meneguhkan betapa multikulturalisme merupakan satu teks yang eksistensinya layak untuk terus disemaikan dalam setiap kinerja kebudayaan, kapan dan dalam konteks apa pun, termasuk yang utama adalah dalam ranah pendidikan.

Pada ranah pendidikan yang lebih spesifik, yakni pada disiplin seni, khususnya lagi dalam konteks ini Seni Rupa misalnya, eksistensi filsafat multikulturalisme bahkan telah lama menjadi salah satu roh vital ketika memang basis kinerjanya disiplin seni berkutat pada domain ordinat estetika. Totalitas praksis kreasi-estetis seni rupa, baik dalam ranah yang berorientasikan seni murni maupun terapan, keduanya sama-sama memegang teguh salah satu prinsip penting yakni penghargaan akan representasi 'uniqueness' sebagai jangkar dan aras kesadarannya. Tafsir klasik atas 'uniqueness' ini, tipikal stereotipnya adalah penghargaan atas teks keberbedaan. Artinya, penghargaan pula atas paham multikulturalisme. Namun prinsip-prinsip paradigmatik multikultural dalam ranah seni sebagaimana dimaksud, dalam praksisnya kerap ditemukan fenomena pengingkaran terutama ketika jagad seni juga tak mampu keluar dari cangkang dan kutukan modernisme. Dampak krusialnya adalah adanya kecenderungan kritik terhadap eksistensi seni yang relatif kurang berdaya dalam mengemban misi imperatif katarsisnya, sebagai salah satu pilar vital bagi kanal pembebasan dan pencerahan kebudayaan.

\section{PEMBAHASAN \\ Miskonsepsi Paradigma Multikultural}

Untuk memahami konsep 'multikultural' secara ontologis adalah dengan cara mengembalikannya konsep tersebut pada akar makna kebudayaan itu sendiri (Suparlan, 2002), karena memang kata multikultural itu dibentuk dari istilah 'kultur' yang diberi awalan 'multi'. Kata 'multi' berarti banyak, lebih dari satu, lebih dari dua, atau berlipat ganda (Anton M, 2005: 761). Makna kata 'kultur', tidak memiliki keketatan 
apalagi monodimensi. Kroeber \& Kluckhohn menegaskan, culture has many definitions and conceptualizations(Kroeber \& Kluckhohn, 1952). Akana tetapi, ada substansi besar yang dapat diekstrakkan untuk memayungi kompleksitas pemahaman teks kebudayaan sebagaimana dimaksud, yaitu sebagai keseluruhan aspek kehidupan masyarakat yang mana pun dan tidak hanya mengenai sebagian dari cara hidup itu (Ihromi, 2000: 18). Pemahaman ini paralel dengan pemaknaan klasik dalam Antropologi, yang memandang kebudayaan sebagai keseluruhan gagasan, tindakan, dan hasil karya manusia dalam rangka kehidupannya, yang dijadikan milik diri mereka dengan cara belajar (Koentjaraningrat, 1990: 180). Jika disandarkan pada pengertian kebudayaan yang begitu plastis dan luas cakupannya tersebut, mestinya pengertian konsep 'multikultural' juga harus mampu mengkerangkai holistisitas keplastisan potensi persoalan yang mungkin ada dalam kerangka kebudayaan tersebut.

Akan tetapi, realitasnya adalah tidak demikian, pemahaman tentang multikultur selama ini telah terjadi miskonsepsi, yang disebabkan semata-mata dikaitkan dengan persoalan etnisitas dan rasialitas. Kata kunci 'perbedaan' yang senantiasa menjadi konsep sentral dalam diskursus multikulturalisme mestinya tidak direduksi dalam dialektikanya semata-mata dengan persoalan etnisitas dan rasialitas, melainkan mencakup keseluruhan kompleksitas dimensi lain yang melekat dalam diri kebudayaan itu sendiri, misalnya terkait dengan ranah psikologis, sikap, usia, jenis kelamin, sistem nilai, kebiasaan, adat-istiadat, dan lain sebagainya (Sinagatullin, 2003: 85). Implikasi pemahaman reduksionis atas paradigma multikultural tersebut, akhirnya juga berimbas pada penyempitan makna tentang konsep 'pendidikan multikultural' yang berkembang di masyarakat, yang juga tak lebih dari pergulatannya dengan wacana persoalan etnisitas semata (Sinagatullin, 2003: 5).

Paradigma multikultural mestinya merupakan terninologi kebudayaan yang luas, yang prinsip terdasarnya sadalah 'antihegemoni' (Goldberg, 1994: 3). Atau dalam kata-katanya Schubert, "conceptualized multiculturalism as a 'counter-hegemony' movement" (Schubert, 2002: 45). Demikian juga halnya ketika paradigma multikultural itu dikerangkakan dalam ranah pendidikan, mestinya juga harus sebagai sebuah 'metadiscipline', yang di dalamnya mencakup: "content integration, the knowledge construction process, prejudice reduction, an equity pedagogy, and an empowering school culture and social structure". Tujuan akhirnya adalah sebagai jembatan emas yang akan mengantarkan subjek didik terinternalisasi nilai-nilai 'pervasive culture', sebagai tiket utama untuk mewujudkan apa yang diistilahkan dengan'cultural mosaic' (Mio, 1999: 72) dan 'cultural sustainaibilty' (Bekerman \& Kopelowitz, 2008: 5).

\section{Bias Gender: Historis dan Historiografi Seni Rupa yang Berjenis Kelamin}

Salah satu persoalan yang krusial terkait dengan wacana 'perbedaan' yang selalu menampak dalam setiap lintasan kebudayaan kapan pun dan di mana pun, termasuk dalam konteks ini adalah dalam jagad seni rupa adalah persoalan yang berbasis jenis kelamin, yakni maskulinitas dan feminitas (Hofstede, 1991; 1998). Persoalan ini dalam wacana studi termutakhir banyak dielaborasi dengan bingkai paradigma 'gender' (Crystal, 1991: 487). Secara sederhana, substansi yang melekat dalam fokus ini, adalah kritik atas realitas kebudayaan selama ini, yang tanpa disadari adalah 'berjenis kelamin laki-laki' (androcentric) karena seksisnya. Kondisi ini berujung pada munculnya sekian deret fenomena ketidakadilan yang nyaris sempurna, terutama yang menimpa kaum perempuan, yang terinternalisasi dalam segala sistem pranata kebudayaan yang ada, kapan pun dan di mana pun.

Lanskap seperti ini tak steril juga, bahkan dapat dikatakan sebagai satu persoalan serius dalam tradisi historis dan historiografi seni rupa, baik Indonesia maupun dunia. 
Hal itu dapat dijumpai dengan amat segera misalnya, dalam dataran wacana baik yang menyangkut 'tokoh' maupun 'pokok'. Pertama, terkait dengan wacana 'tokoh', kritik ini bisa dimulai dari pencarian posisi seniman perempuan dalam sejarah kesenirupaan kita. Jika diajukan pertanyaan, “Adakah perupa (besar/jenius) perempuan dalam sejarah seni rupa kita?" Maka upaya mencari jawaban atas pertanyaan ini, kerap akan berujung sia-sia, karena fakta menunjukkan historis dan historiografi seni rupa itu ter(di)susun melalui suatu prosedur dan protokol yang tipikal yaitu' patriarki' (Mies, 1986), yang berbasiskan bias ideologi 'gender'. Oleh karena itu, tidak mengherankan, jika daftar nama seniman pencipta sejarah seni rupa, baik dunia maupun Indonesia, catatannya tak beranjak dari sederetan nama tokoh seperti Picasso, Rembrant, David, Michelangelo, Van Goch, Davinchi, Pollock, Raden Saleh, Affandi, Basuki Abdullah, Sudjojono, dan sederetan nama lainnya, yang semuanya adalah laki-laki. Demikian juga halnya dengan nama-nama untuk para intelektual, kritikus, serta kurator seninya, yang ada adalah juga deretan daftar lakilaki. Itulah sebabnya, upaya mencari kehadiran 'Sudjojono perempuan' atau 'Michelangelo perempuan' dalam peta sejarah seni rupa Indonesia dan dunia misalnya, bisa akan berakhir sia-sia (Supriyanto, 2001).

Griselda Pollock dalam "Pengantar" untuk buku Vision and Difference: Femininity, Feminism, and the Histories of Art (1988), yang diadaptasi Enin Supriyanto karenanya menegaskan bahwa fenomena tersebut adalah salah satu pokok penting yang selama ini luput dalam kritik dalam historis dan historiografi modern dunia, yaitu tidak hadirnya perupa perempuan sebagai bagian penting dari perkembangan seni rupa modern dunia, yang kemudian menyarankan untuk menguji ulang berbagai historisitas seni rupa modern selama ini, sebagai bagian dari upaya yang disebutnya: 'intervensi feminis ke dalam sejarah seni rupa' (Supriyanto, 2001). Hal ini sedikit banyak sejalan dengan rumusan kritis dari Louis Althusser, yang me- yakini bahwa dalam setiap konsep, wacana, atau disiplin itu, selalu bisa dilacak kehadiran selubung ideologis, tempat makna dan nilai dari berbagai konsep dan disiplin ilmu itu disandarkan.

Pada sisi perspektif 'pokok' tampaknya juga tidak jauh berbeda, yaitu arus utama tematik representasi seni rupa Indonesia, sosok laki-laki tetap sebagai subject matter yang didedahkan dominan, jika dibandingkan dengan perempuan. Secara tradisional perempuan lebih tampak mengedepan dalam stereotip yang sudah terstigma, di antaranya yang paling menonjol adalah sebagai penanda pesan-pesan penggugah berahi, dalam wujud figur-figur telanjang, dan visualisasi domestikisasi eksistensi dirinya, baik di ranah domestik maupun publik (Kasiyan, 2007). Kenyataan yang hampir sama dan bahkan jauh lebih kitsch maknanya, adalah yang terjadi dalam wacana applied Art yang berbasiskan budaya massa misalnya, sebagaimana yang terdapat dalam karya-karya desain komunikasi visual, seperti periklanan, di mana perempuan menjadi taruhan komodifikasi-estetis utama, melalui eksploitasi, manipulasi, dan dehumanisasi tubuhanya (Kasiyan, 2006, 2008).

Singkatnya, perempuan sampai hari ini masih merealitas sebagai objek yang merayakan ketakberdayaan. Di sinilah perempuan meng-ada dalam sejarah seni khususnya dan peradaban pada umumnya, tak lebih sebagai apa yang diistilah sebagai sosok 'second sex' (de Beauvoir, 2003: x). Adagium klasik yang menegaskan bahwa 'perempuan tanpa sejarah' dan 'sejarah tanpa perempuan' menemukan bukti dan verifikasi sahihnya dalam hal ini (Purwanto, 2006: xviii). Kuntowijoyo pernah memerkarakan realitas ini, dan mencoba mencari jawab akan akar pesoalan yang dapat dirujuk, dan menemukan satu jawabankarena konstruksi sejarah yang menarik perhatian secara konvensional adalah sejarah yang memang dipenuhi dengan tema-tema sejarah politik dan militer. Sejarah politik dan militer adalah sejarah tentang kekuasaan dan keperkasaan, dua hal yang selalu menjadi 
milik kaum laki-laki. Oleh karena itu, rekonstruksi sejarah kita bercorak 'androcentric', sejarah berpusat pada kaum laki-laki saja (Kuntowijoyo, 2003: 115).

Lanskap yang agak berbeda akan didapatkan, jika fenomena yang yang ada dalam realitas historis dan historiografi seni rupa Indonesia tersebut, dibandingkan dengan fenomena yang terdapat dalam disiplin seni yang lain, taruhlah dalam seni tari, musik dan juga sastra. Di ketiga disiplin seni tersebut perempuan, baik sebagai tokoh maupun pokok telah menjadi bagian yang relatif jauh lebih bermartabat dan bermakna.

\section{Bias Fine Art dan 'Homonisasi' Visual Art}

Paling tidak ada dua basis pijakan yang dapat dijadikan pintu masuk bagi pemahaman problem 'hegemoni' dalam seni rupa Indonesia ini, yaitu pertama, dilihat pada dataran 'praktik wacana', dan kedua di 'wacana praktik' yang termanifesto secara sosiologis di masyarakat. Pertama, di tingkat 'praktik wacana', sandaran yang paling kuat dapat dijangkarkan pada analisis terkait dengan bagaimana wacana seni rupa itu meng-ada terutama dalam strukturasi disiplin akademi mulai dari sekolah dasar sampai perguruan tinggi. Hasilnyamenunjukkan, betapa strukturasi kajian teoretik disiplin seni rupa itu, tipikalnya cenderung mengafirmasi pandangan yang sudah tereduksi terlampau jauh tentang wacana seni rupa mayor (hight art) dan fine art, dengan mainstream-nya lukisan, patung, dan grafis. Sebaliknya, khazanah visual art lain di luar itu, misalnya yang berbasiskan pada etnik tradisi, seperti Kriya dan atau Kerajinan nyaris tak pernah masuk menjadi bagian narasi besar karena stereotip sosiologisnya terlanjur dianggap sebagai low art yang tak penting. Berdasar dari kenyataan itulah, kiranya perlu apa yang dinamakan dengan revitalisasi paradigma keilmuan seni di perguruan tinggi agar kita tidak selalu merasa 'lack of discourse' and 'lack of knowledge' (Kasiyan, 2004).

Kedua, yaitu problem elitisme di tingkat 'wacana praktik', yang pemahamannya paling tidak dapat dikerangkakan dari aras analisis terkait dengan bagaimana realitas praksis seni rupa Indonesia itu menyejarah di masyarakat. Fakta empiris di ranah ini, juga akan menghasilkan konklusi sama, yeitu mainstream-nya juga tetap didominasi oleh seni rupa mayor fine art sebagai high art yang bersumber dari spirit 'avant-gardism'. Realitas masih bersaksi betapa dominasi dan superioritas fine art sampai hari ini, bahkan harus ditebus dengan semakin inferioritasnya pada banyak dimensi visual art lain, misalnya 'seni Kriya', relatif tak mendapat ruang penghargaan yang memadai, bahkan semakin lebih tragis lagi di era kontemporer ini (Kasiyan, 2009). Inilah yang penulis maksud telah terjadi 'homonisasi' dalam historis dan historiografi seni rupa Indonesia selama ini, yaitu "seni rupa telah menjadi serigala bagi 'seni rupa yang lain'-nya".

\section{Bias 'Barat-Jawasentrisme'}

Problem lain dalam seni rupa Indonesia terkait dengan eksistensi multikultural adalah konstelasinya yang selama ini mengafirmasi dua patron sentralistis, yaitu Barat dan lokal-etnik, terutama Jawa. Pertama, patronase Barat telah menjadi keniscayaan terkait dengan dampak penjajahan Barat yang menimpa bangsa-bangsa bekas jajahan itu, berupa keterbelahan sikap dalam perkembangan budaya mereka. Bagaimana konsepkonsep modernitas yang ditawarkan kolonialisme Barat itu begitu memesona, sehingga hampir seluruh planet bumi ini akhirnya dikuasai oleh norma-norma Barat. Di negara-negara postkolonial segala infrastruktur, konsep kebijaksanaan, dan bahkan ideologinya merupakan fotokopi negara-negara kolonial. Perbedaannya adalah para penguasanya saja yang berganti warna kulit. Yang terjadi hanyalah 'palihan nagari' atau 'scheuring van het rijk' karena struktur sosial budayanya masih sama seperti pada masa kolonial (Onghokham, 2009: 163-164). Edward Said lewat Orientalism-nya mengintrodusir fenomena ini sebagai sebentuk realitas 'postkolonial' (Said, 1979).

Kolonialisme telah menciptakan realitas budaya tersendiri yang khas bagi bangsa 
terjajah yang nyaris mirip di seluruh dunia, yang salah satunya adalah memanifesto dalam bentuk ketidakmampuannya untuk merumuskan masa depan. Masa depan itu tidak merealitas di benak para korban penjajahan, di luar jangkauan, di tangan orang lain, bahkan menjadi milik orang lain. Untuk merumuskan masa depan itu, membutuhkan apa yang dinamakan dengan 'pengetahuan', baik pengetahuan alam maupun pengetahuan buatan. Pengetahuan alam mengandung kadar keharusan, sedangkan pengetahuan buatan, mengandung kadar pilihan. Pemahaman akan adanya keharusan dan pilihan seperti itu membutuhkan tradisi tersendiri, yang akan bertanggungjawab atas himpunan kadar pilihan yang tersusun dan kemudian diyakini dan dipeluknya (Saliya, 2002: 44). Akan tetapi, sejarah menunjukkan bahwa bangsa-bangsa terjajah, tidak pernah memiliki pengetahuan dan pilihan-pilihan itu.

Pilihan merupakan hak preogratif sang penjajah. Bagi kaum terjajah, pilihan adalah suatu kemewahan. Kalaulah bukan di tangan orang lain, nasibnya berada di luar jangkauan, atau sama sekali di luar kesadaran kulturalnya. Oleh karena itu, nyaris semua kepranataan pengetahuannya bangsabangsa bekas jajahan itu merupakan barang pinjaman atau bersumber dari Barat (Saliya, 2002:44). Termasuk dalam konteks ini adalah pengetahuan dalam bidang seni rupa. Hal ini dapat dirunut sejak awal perkembangan seni rupa modern Indonesia mulai era Raden Saleh, Mooi Indië, Gerakan Seni Rupa Baru, sampai Kontemporer, yang selalu mengikuti pola seni rupa Barat (Burhan, 2006: 275). Estetika seni rupa Indonesia adalah juga mengafirmasi penuh estetika Barat (Sutrisno, 1993; Gie, 1996; Djelantik, 1999; Sumardjo, 2000). Oleh karena itu, Linda Tuhiwai Smith menyarankan untuk melakukan 'dekolonisasi metodologi' atas segala konstruksi epistemis-historis yang kita miliki. (Smith, 2005).

Kedua, yaitu persoalan 'Jawasentrisme' dalam praksis kesenirupaan Indonesia, baik dalam format fine art maupun applied art.
Dalam format fine art misalnya, dapat dilihat betapa selama ini Jawa, terutama Yogyakarta dan Bandung, adalah pusat wacana segala-galanya bagi penjelasan perkembangan seni rupa Indonesia, sejak sebelum modern hingga kontemporer (Rahardjo, 2009: 8). Hal itu akan menafikkan fakta kekayaan eksistensi dan perkembangan seni Kriya di wilayah lain di Indonesia, yang bukan hanya juga amat kaya dan beragam, melainkan juga memiliki jejak dan akar historis yang tak kalah panjang di masa lampau. Kerajinan batu dan batu belah yang ada di Kalimantan tepatnya di situs gua Niah Sarawak misalnya, sudah ada sejak 40.000 tahun SM; kerajinan Toali, berupa 'microlith' di wilayah Maros Sulawesi Selatan, ada sejak 8000 tahun lampau; di Sulawesi Utara, tepatnya di semenanjung Minahasa, dekat danau Tondano, kerajinan sudah ada sejak 6000 tahun SM; serta di Timor dan Flores yang sudah ada sejak 13.000 tahun lampau (Munoz, 2009: 19-22).

Demikian juga halnya dengan fakta historis lain, ketika Indonesia masih dalam Era Kolonisasi Belanda, kekayaan khazanah Kriya kita yang ada membentang di seantero Nusantara, pernah menjadi kebanggaan yang amat luar biasa bagi pemerintahan kolonial Belanda, ketika diikutkan dalam acara 'Exposition Coloniale Internationale' (Festival Akbar Para Penjajah) di Bois de Vincennes Paris Perancis pada musim semi 1931. Anjungan pemerintah kolonial Belanda yang memamerkan berbagai khazanah produk kebudayaan dari negeri jajahannya (terutama Indonesia), berupa karya-karya kriya etnik yang sebagian besar berasal dari luar Jawa, yaitu mulai dari Sumatera, Sulawesi, Bali, sampai Papua, betapa mendapatkan penghargaan teringgi dan paling berhasil menghipnotis lebih dari 34 juta pengunjung, karena karya-karya kriya yang dihadirkan langsung dari Indonesia itu sungguh amat luar biasa, hingga konon katanya manampak bak pemandangan di negeri dongeng (Gouda, 2007: 344-407).

Pada derivat lebih jauh lagi, proyek Jawanisasi ini juga menemukan legitimasi 
akademiknya, ketika misalnya buku-buku kajian tentang perkembangan seni rupa Indonesia juga banyak dijangkarkan berlokuskan Jawa. Claire Holt misalnya, lewat Art in Indonesia: Continuities and Change, yang pertama kali diterbitkan oleh Cornell University Press di Ithaca New York (1967) dan kemudian diterjemahkan oleh R.M. Soedarsono menjadi Melacak Jejak Perkembangan Seni di Indonesia (2000), juga menempatkan Jawa sebagai situs utama ketika menarasikan tentang sejarah seni rupa Indonesia sejak zaman prasejarah hingga modern (Holt, 2000).

Pertanyaannya adalah mengapa mesti Jawa? Denys Lombard lewat Magnum Opusnya: Le Carrefour Javanais: Essai d'Historie Globale (1990) pernah memberikan jawabannya bahwa memang Jawa adalah merupakan salah satu pusat kebudayaan yang kerap merepresentasikan Indonesia. Marco Polo misalnya, untuk menggambarkan betapa besar dan bermaknanya Jawa, ketika membincangkan tentang Indonesia, dalam bukunya La Description du Monde, (1955) menyebut Pulau Jawa sebagai 'Jawa Besar' atau 'Jawa Mayor', untuk membedakan dengan tetangganya, Sumatera misalnya, yang dinamakannya dengan istilah 'Jawa Minor'. Meski luas pulau Jawa hanya sekitar tiga kali lebih kecil daripada Sumatera, tetapi dari mana pun kita menelaah kepulauan Indonesia, harus diakui bahwa Jawa memang menonjol.

Kekaguman Marco Polo itu juga ada pada para musafir yang datang sesudahnya, semua memberikan kepada Jawa tempat utama dalam kisah dan kajian mereka. Di pulau itulah masa prasejarah dimulai, dengan ditemukannya sisa-sisa pithecanthropus erectus di pusat pulau, di Trinil, di lembah Bengawan Solo. Di pulau itu pula, dimulai 'sejarah' Indonesia, dengan ditemukannya batu bertulis pertama di sebelahnya. Sampai abad ke-15, dokumen-dokumen arkeologi dan epigrafi dari Jawa Tengah dan Jawa Timur akan menyajikan inti dari dokumentasi bagi sejarawan. Pada abad ke-14, pulau Jawa menjadi pusat dari sebuah sistem pelayaran antarpulau yang sangat canggih, yaitu 'imperium Majapahit', yang dalam arti tertentu merupakan citra penyatuan-penyatuan Nusantara yang dicapai kemudian.

Pada abad ke-15, Islamisasi pantai utara menandai munculnya sebuah tata ekonomi dan sosial baru. Pada abad ke-16, ketika sumber-sumber Barat membawa informasi baru tentang daerah tersebut, terungkap lah betapa pentingnya kota-kota pelabuhan dagang di pesisir itu, terutama Kesultanan Banten, di barat. Jelaslah bahwa keputusan Belanda untuk menetapkan bandar utama mereka di dekat tempat tersebut bukan suatu kebetulan. Dengan menetap di Batavia, mereka mengakui dan sekaligus memperkuat kedudukan utama pulau Jawa. Kini, dengan berpusat di Jakarta pulalah, wilayah Indonesia mengambil bentuk (Lombard, 1996: 18-19).

Demikian juga bagi Thomas Stamford Raffles misalnya, Jawa juga merupakan satu situs yang dianggap amat memukau, selama ia berada di Indonesia, yang dimulai pada tahun 1811, ketika disertakan dalam rombongan ekspedisi ke tanah Jawa sebagai Letnan Gubernur (Lieutenant Governor of Java), di bawah perintah Gubernur Jenderal (di India) Sir Gilbert Elliot Murray-Kynynmod (1751-1814) atau yang lebih dikenal dengan Lord Minto, dan kemudian menjadi Gubernur Jenderal (1811-1816). Selama kepemimpinannya yang sebenarnya hanya lima tahun itu, dan didorong oleh keterpukauannya yang luar biasa atas Jawa, dihasilkannya karya masterpiece-nya The History of Java yang amat klasik dan melegenda itu (Raffles, 2008).

Akan tetapi, semua bukti risalah historis maupun akademis itu, kiranya tetap tak cukup memadai untuk digunakan sebagai rujukan legitimasi atas persoalan hegemoni. Bahkan atas nama apa pun, yang dinamakan hegemoni dalam konteks berkebudayaan apa pun, kapan pun, dan di mana pun, tetap juga tak pernah dapat ditoleransi, karena sebagaimana diteguhkan oleh Nietzsche, memang kerapkali praksis hege- 
moni pengetahuan itu sebenarnya ujungujungnya bermuara pada motif 'kehendak untuk berkuasa' (Der Wille zur Macht) semata (Sunardi, 2001: vii).

Dengan demikian, Jawa dengan segala warna ideologi kebudayaannya, betapa telah menjadi sebentuk situs trauma, yang dengan hegeominya telah mengukuhkan dirinya sebagai sang pusat, sentral, superior, dan menjadi patron, sebaliknya, etnik-etnik lainnya di luar Jawa sebagai client yang berada dalam ordinat peripheral, dan karenanya selalu menderita 'inferior complex' yang tak berujung sudah. Model dialektika budaya yang dibangun seperti ini, betapa tanpa disadari telah menempatkan etnik-etnik di luar Jawa, seolah menjadi semacam 'subaltern', 'the other' (sang liyan), yang keberadaannya harus di-Jawa-kan, jika ingin masuk altar terhormat, situs harmoni sah di negeri ini (Loomba, 1998: 22). Model-model penyeragaman kebudayaan etnik Nusantara ini, dalam jangka panjang, betapa hasilnya sudah dapat dituai dan disaksikan: destruktivitas konflik kedaerahan yang berkembang dalam banyak varian yang sulit diselesaikan, karena memang jejaring pengaman kearifan budaya lokal sebagai modal sosialnya, telah banyak yang musnah ter(di)hancurkan. Dari sini dapat dilihat bahwa setiap politik penyeragaman hanya akan mematikan ke-Indonesiaan dalam pembekuan teks yang sekarat dan layu (Sutrinso, 2004: 6).

Jawanisasi yang menyejarah panjang ini, menjadi begitu bertele-tele dan sulit untuk diurai, meski zaman bukan hanya telah beringsut, tetapi sudah berganti, yang disebabkan masih cukup dominannya kultur feodalisme, yang disokong oleh satu 'Teologi Priyayi', yang konon risalahnya berbeda benar jika dibandingkan dengan teologiteologi lain, taruhlah: Teologi Ortodoks dan Teologi Pembebasan. Jika Teologi Ortodoks ingin mengubah manusia untuk mengubah dunia, dan Teologi Pembebasan, ingin mengubah dunia untuk mengubah manusia, maka Teologi Priyayi ingin mengubah manusia untuk tidak mengubah dunia (Arsuka, 2002: 325). Terkait dengan hal inilah,
Loomba mengkritisi tentang perspektif sempit atas tafsir postkolonialisme yang ada selama ini, yang semata-mata penjajahnya itu dialamatkan ke Barat, padahal kolonisasi terbukti juga banyak dilakukan oleh diri-internal budayanya sendiri (Loomba, 1998: 22).

\section{Seni Rupa Kontemporer: Harapan Oasis Multikultural}

Pelbagai problem baik seksis, elitis-hegemonik, maupun Barat-Jawasentris tersebut, sedikit banyak harapannya bisa dicairkan dengan kehadiran wacana Kontemporer dalam sejarah seni rupa Indonesia, yang gelagat momentumnya mulai memiuh di seputar era '90-an, yang ditandai dengan begitu mengedepannya spirit kebaruan yang diusungnya, yang menyediakan ruang toleransi luar biasa bagi terminologi 'perbedaan', baik dari sisi basis material, medium, keteknikan, maupun subject matter-nya dalam berkarya seni (Marianto, 2000). Fenomena perayaan atas 'perbedaan' dan keberagaman ini, bahkan kemudian tetap menjadi pemandu spirit utama dan terdepan bagi pencapaian puncak-puncak perkembangan art world seni rupa Indonesia sampai tahun 2000 -an belakangan. Namun dari berbagai realitas yang menampak ke permukaan, dari begitu banyaknya representasi ke-kontemporer-an yang ada, ternyata tetap tidak atau paling tidak belum mampu merapuhkan ingatan apalagi menggeser akan maisntream mitos kutukan yang telah mapan dalam tradisi Seni Rupa Modern Indonesia yang sudah terbentuk sangat lama itu.

Secara sosiologis bahkan bangunan imperium seni rupa Kontemporer, yang cenderung tampil kelewat 'seksi', dengan mengafirmasi kredo ideologi 'anything goes', dengan tingkat sofistikasi yang melampaui pemahaman publik, fenomenanya banyak yang masih menjadi wilayah asing, bahkan tak jarang keberadaanya diprotes, karena dianggap mengganggu dan menimbulkan ketidaknyamanan. Di sinilah dapat dilihat, betapa usaha-usaha keras dan panjang yang 
dilakukan oleh seni selama ini, ternyata tidak atau belum berhasil mendidik publik untuk dekat dengan kesenian. Atau lebih tepat sebaliknya: tidak atau belum berhasil mendidik kesenian untuk menjadi dekat dan integral bagi kehidupan publik; menjadi salah satu sumber identifikasi persoalan dan diri publik itu sendiri (Dahana, 2001: 170). Karenanya manakala ditimbang secara benar, fenomena ke-Kontemporer-an yang mewajah dalam historis dan historiografi seni rupa Indonesia, terutama dalam kelindannya dengan paradigma multikultural, pada taraf tertentu dapat diatribusi sebagai sebentuk realitas yang cenderung 'involutif' (Kleden, 1995: 134-135; Geertz, 1983).

\section{SIMPULAN}

Sebagai penutup dapat ditegaskan lagi bahwa hakikat makna multikultural itu baik dalam persepktif makrokultur yang luas maupun mikrokultur seperti dalam disiplin seni misalnya, adalah bukan sebagai pilihan, melainkan keharusan. Persoalannya kemudian adalah mau kita, baik perupa atau seniman, pendidik seni, pecinta seni, maupun masyarakat dalam arti luas memberi tafsir ulang yang lebih inklusif dan terbuka atas realitas quo-vadis itu, jika kita masih bersepakat mengidealkan seni sebagai salah satu situs penting yang menggendhong visi-nilai 'katarsis' bagi pemuliaan peradaban dan kehidupan yang kodrat sejatinya adalah memang plural, multikultural. Hingga harapannya akan mampu dihadirkan risalah kompleksitas ekspresi-kreatif-estetis seni rupa dengan segala narasi besarnya yang tak hanya cenderung tunggal, melainkan multi dan plural.

Kita mestinya dapat melihat tidak hanya ada satu sejarah, tapi sejarah-sejarah, banyak sejarah, bahkan awan debu sejarahsejarah (Dewanto, 1996: 44). Paradigma multikultur mengajarkan pada kita, terutama tentang hakikat 'liyaning liyan', menghormati yang-beda dalam keberbedaannya dan yang-lain dalam kelainannya. Paradigma multikultural membukakan keluasan horizon cakrawala pada kita, sebuah afir- masi akan 'Yang-Lain'. Ia meneguhkan pentingnya penghargaan atas teks perbedaan, di tengah dunia yang dibayang-bayangi hasrat akan kebenaran yang 'utuh' dan 'tak retak'.

\section{DAFTAR PUSTAKA}

Arsuka, N. A., 2002, "Priyayi, Kerja, dan Sejarah", dalam Esay-esay Bentara 2002. Jakarta: Penerbit Buku Kompas.

Bekerman, Z. and Kopelowitz. E., (eds.), 2008, "Introduction", in Cultural Education-Cultural Sustainability: Minority, Diaspora, Indigenous and EthnoReligious Groups in Multicultural Societies. New York \& London: Routledge.

Burhan, M. A., 2006, “Seni Rupa Kontemporer Indonesia: Mempertimbangkan Tradisi", dalam Jaringan Makna Tradisi Hingga Kontemporer: Kenangan Purna Bhakti untuk Prof. Soedarso Sp., M.A. Yogyakarta: BP ISI Yogyakarta.

Crystal, D., (ed.), 1991, The Cambridge Encyclopedia. New York: Cambridge University Press.

Dahana, R. P., 2001, "Seni yang Asyik Sendiri", dalam Kebenaran dan Dusta dalam Sastra. Magelang: Indonesiatera.

de Beauvoir, S., 2003, Second Sex: Fakta dan Mitos. Terjemahan Toni B. Febriantono. Surabaya: Pustaka Promothea.

Djelantik, A.A.M, 1999, Estetika: Sebuah Pengantar. Cetakan Pertama. Bandung: MSPI.

Geertz, C., 1983, Involusi Pertanian. Jakarta: Bhratara Karya Aksara.

Gie, T.L., 1996, Filsafat Keindahan. Edisi Pertama, Cetakan Pertama. Yogyakarta: Pusat Belajar Ilmu Berguna.

Goldberg, D. T., (ed.), 1994, Multiculturalism: A Critical Reader. Oxford: Blackwell.

Gouda, F., 2007, “Bab 6: Anjungan Hindia Belanda Terbakar: Kehadiran Belanda di Pameran Kolonial se-Dunia di 
Paris, 1931", dalam Dutch Culture Overseas: Praktik Kolonial di Hindia Belanda, 1900-1942. Terjemahan Jugiarie Soegiarto \& Suma Riella Rusdiarti. Cetakan Kedua. Jakarta: PT Serambi Ilmu Semesta.

Hofstede, G, 1991, Cultures and Organizations: Software of the Mind. London: McGraw-Hill.

Holt, C., 2000, Melacak Jejak Perkembangan Seni di Indonesia. Terjemahan R.M. Soedarsono. Cetakan Pertama. Bandung: Masyarakat Seni Pertunjukan Indonesia.

Ihromi, T.O, 2000, "Konsep Kebudayaan", dalam Pokok-pokok Antropologi Budaya. Edisi Kesebelas. Jakarta: Yayasan Obor Indonesia.

Kasiyan, 2004, “Revilatisasi Paradigma Keilmuan Seni di Perguruan Tinggi", dalam Imaji, Jurnal Seni dan Pendidikan Seni Fakultas Bahasa dan Seni Universitas Negeri Yogyakarta, Edisi April.

, 2006, "Komodifiaksi Seks dan Pornografi dalam Estetika Iklan di Media Massa". Laporan Penelitian Tidak Diterbitkan. Lembaga Penelitian, Universitas Negeri Yogyakarta.

2007, “Tema Perempuan dalam Seni Rupa Kontemporer Yogyakarta: Tinjauan Perspektif Gender". Laporan Penelitian Kajian Wanita Tidak Diterbitkan. Yogyakarta: Lembaga Penelitian Universitas Negeri Yogyakarta.

, 2008, Manipulasi dan Dehumanisasi Perempuan dalam Iklan. Cetakan Pertama. Yogyakarta: Ombak.

, 2009a, "Seni Kriya dan Kearifan Lokal: Tatapan Postmodern dan Postkolonial", dalam Suwarno Wisetrotomo (ed.), Lanskap Tradisi, Praksis Kriya, dan Desain: Cendera Hati Purnabhakti untuk Prof. Drs. SP. Gustami, SU. Cetakan Pertama. Yogyakarta: BP ISI Yogyakarta, Maret.
Kleden, I., 1985, "Pembaharuan Kebudayaan: Mengatasi Transisi", dalam Prisma, Edisi 8.

Koentjaraningrat, 1990, “Bab V Kebudayaan", dalam Pengantar Ilmu Antropologi. Cetakan Kedelapan. Jakarta: PT Rineka Cipta.

Kroeber, A. L. and Kluckhohn. C., 1952, Culture: A Critical Review of Concepts and Definitions. New York: Vintage Books.

Kuntowijoyo, 2003, "Sejarah Wanita: dari Sejarah Androcentric ke Sejarah Androgynous", dalam Metodologi Sejarah. Edisi Kedua. Yogyakarta: Tiara Wacana.

Loomba, A., 1998, Colonialism/Postcolonialism. London: Routledge.

Margalit, A. and Raz. J., 1995, "National Self-Determination", in Will Kymlicka, (ed.), The Rights of Minority Cultures. New York: Oxford University Press.

Marianto, M. D., 2000, “Gelagat Yogyakarta Menjelang Millenium Ketiga", dalam Jim Supangkat, et al., Outlet: Yogya dalam Peta Seni Rupa Kontemporer Yogyakarta. Yogyakarta: Yayasan Seni Cemeti Bekerjasama dengan Prince Claus Fund for Culture and Development Belanda.

May, S., (Ed.), 1999, "Introduction: Towards Critical Multiculturalism", in Critical Multiculturalism: Rethinking Multicultural and Antiracist Education. Philadelphia: Falmer Press.

Mies, M., 1986, Patriarchy and Accumulation on a World Scale: Woman in the International Division of Labour. Avon: The Bath Press.

Mio, J. S., et al, 1999, Key Words in Multicultural Interventions: A Dictionary. Westport, Connecticut, London: Greenwood Press.

Munoz, P. M., 2009, "Prasejarah", dalam Kerajaan-kerajaan Awal Kepulauan Indonesia dan Semenanjung Malaysia: Perkembangan Sejarah dan Budaya Asia Tenggara (Jaman Prasejarah-Abad XVI). 
Terjemahan Tim Media Abadi. Cetakan Pertama. Yogyakarta: Mitra Abadi.

Onghokham, 2009, “India yang Dibekukan: Mooi Indië dalam Seni Rupa dan Ilmu Sosial", dalam Harsya W. Bachtiar, Peter B.R. Carey, dan Onghokham, Raden Saleh: Anak Belanda, Mooi Indie, dan Nasionalisme. Jakarta: Komunitas Bambu.

Purwanto, B., 2006, Gagalnya Historiografi Indonesiasentris?, Yogyakarta: Ombak.

Raffles, T. S., 2008, The History of Java. Terjemahan Eko Prasetyaningrum, et al. Yogyakarta: Narasi.

Raharjo, T., 2009, “Industri Kriya sebagai Media Percepatan Kesejahteraan Ekonomi Kerakyatan", dalam Prosiding Seminar Nasional Seni Kriya: Kriya, Kesinambungan dan Perubahan, yang diselenggarakan oleh Jurusan Kriya, Fakultas Seni Rupa, ISI Yogyakarta, dalam rangka Purnatugas Prof. Drs. SP. Gustami, S.U. Yogyakarta: Lembaga Pengkajian dan Penerbitan Seni Kriya ISI Yogyakarta.

Said, E. W., 1979, Orientalism. New York: Vintage Books.

Saliya, Y., 2002, "Berkenalan dengan Indonesia: Memahami Bumi dan Isinya" dalam Adi Wicaksono, et al., (eds.), Identitas dan Budaya Massa: Aspek-aspek Seni Visual Indonesia. Yogyakarta: Yayasan Seni Cemeti dan The Toyota Foundation.
Schubert, J. D., 2002, "Defending Multiculturalism: From Hegemony to Symbolic Violence", in American Behavioral Scientist Journal, 2002; 45, London: Sage.

Smith, L. T., 2005, “Bab I: Imperialisme, Sejarah, Penulisan, dan Teori", dalam Dekolonisasi Metodologi. Terjemahan Nur Cholis. Cetakan Pertama. Yogyakarta: INSIST Press, 2005.

Sinagatullin, I. M., 2003, “The Nature of Multicultural Education", in Constructing Multicultural Education in a Diverse Society. Lanharn, Maryland, and London: A Scarecrow Education Book.

Sumardjo, J., 2000, Filsafat Seni. Bandung: Penerbit Institut Teknologi Bandung.

Sunardi, St., 2001, Nietzsche. Cetakan Ketiga. Yogyakarta: LKiS.

Suparlan, P., 2002, "Menuju Masyarakat Multikultural", dalam Makalah Simposium Internasional Bali ke-3. Denpasar Bali, 16-21 Juli.

Supriyanto, E., 2001, "Perempuan, Seni Rupa, dan Sejarah", dalam Kompas, Jum'at, 1 Juni.

Sutrisno, M., 2004, "Rumitnya Pencarian Diri Kultural", dalam Mudji Sutrisno dan Hendar Putranto, (Eds.), Hermeneutika Pascakolonial. Yogyakarta: Kanisius. 